\title{
Clinical expression of cystic fibrosis in a large cohort of Italian siblings
}

\author{
Vito Terlizzi ${ }^{i^{*}}$ D, Marco Lucarelli ${ }^{2}$, Donatello Salvatore ${ }^{3}$, Adriano Angioni ${ }^{4}$, Arianna Bisogno ${ }^{5}$, Cesare Braggion? , \\ Roberto Buzzetti ${ }^{6}$, Vincenzo Carnovale ${ }^{7}$, Rosaria Casciaro ${ }^{8}$, Giuseppe Castaldo ${ }^{9,10}$, Natalia Cirilli ${ }^{11}$, Mirella Collura ${ }^{12}$, \\ Carla Colombo ${ }^{5}$, Antonella Miriam Di Lullo ${ }^{13}$, Ausilia Elce ${ }^{14}$, Vincenzina Lucidi ${ }^{15}$, Elisa Madarena ${ }^{16}$, Rita Padoan ${ }^{17}$, \\ Serena Quattrucci ${ }^{18}$, Valeria Raia ${ }^{19}$, Manuela Seia ${ }^{20}$, Lisa Termini ${ }^{21}$ and Federica Zarrilli ${ }^{22}$
}

\begin{abstract}
Background: A clinical heterogeneity was reported in patients with Cystic Fibrosis (CF) with the same CFTR genotype and between siblings with CF.

Methods: We investigated all clinical aspects in a cohort of 101 pairs of siblings with CF (including 6 triplets) followed since diagnosis.

Results: Severe lung disease had a 22.2\% concordance in sib-pairs, occurred early and the $\mathrm{FEV}_{1} \%$ at 12 years was predictive of the severity of lung disease in the adulthood. Similarly, CF liver disease occurred early (median: 15 years) and showed a concordance of $27.8 \%$ in sib-pairs suggesting a scarce contribution of genetic factors; in fact, only 2/15 patients with liver disease in discordant sib-pairs had a deficiency of alpha-1-antitrypsin (a known modifier gene of CF liver phenotype). CF related diabetes was found in 22 pairs (in 6 in both the siblings). It occurred later (median: 32.5 years) and is strongly associated with liver disease. Colonization by P. aeruginosa and nasal polyposis that required surgery had a concordance $>50 \%$ in sib-pairs and were poorly correlated to other clinical parameters. The pancreatic status was highly concordant in pairs of siblings (i.e., 95.1\%) but a different pancreatic status was observed in patients with the same CFTR mutations. This suggests a close relationship of the pancreatic status with the "whole" CFTR genotype, including mutations in regulatory regions that may modulate the levels of CFTR expression. Finally, a severe course of CF was evident in a number of patients with pancreatic sufficiency.
\end{abstract}

Conclusions: Physicians involved in care of patients with CF and in genetic counseling must be aware of the clinical heterogeneity of CF even in sib-pairs that, at the state of the art, is difficult to explain.

Keywords: CFTR, Genotype, Phenotype, Modifier genes, FEV 1 , Pseudomonas aeruginosa

\section{Background}

Cystic fibrosis (CF) is the most common, severe, autosomal recessive inherited disease among Caucasians [1]. It is usually characterized by elevated sweat chloride levels (SCL), pancreatic insufficiency (PI), progressive lung disease with chronic bacterial infections of lower airways and male infertility due to obstructive azoospermia. More than 2000 variants have been identified in the cystic fibrosis transmembrane conductance regulator

\footnotetext{
* Correspondence: terlizzivito@libero.it

'Dipartimento di Pediatria, Centro Regionale Toscano per la Fibrosi Cistica, Azienda Ospedaliero-Universitaria Meyer, Viale Gaetano Pieraccini 24, 50139 Florence, Italy

Full list of author information is available at the end of the article
}

(CFTR) gene so far (www.genet.sickkids.on.ca), but only few have been functionally characterized [2]. Some of them may be grouped in six classes according to the known effect on CFTR synthesis and/or function [2, 3]. However, although life-expectance and severity of the disease depend on the class of mutations $[4,5]$, there is a wide clinical heterogeneity in CF patients carrying the same CFTR genotype and even between siblings and twins with CF [6]. Several sources contribute to such variability as mutations in non-coding regions of the CFTR gene [7-9], intronic variants [9-11] and complex alleles [12,13] making the genotype-phenotype relationship more complex.

(c) The Author(s). 2018 Open Access This article is distributed under the terms of the Creative Commons Attribution 4.0 International License (http://creativecommons.org/licenses/by/4.0/), which permits unrestricted use, distribution, and reproduction in any medium, provided you give appropriate credit to the original author(s) and the source, provide a link to the Creative Commons license, and indicate if changes were made. The Creative Commons Public Domain Dedication waiver (http://creativecommons.org/publicdomain/zero/1.0/) applies to the data made available in this article, unless otherwise stated. 
In the last decade several studies explored the role of modifier genes of CF phenotype [14] for meconium ileus (MI) [15-17], CF-related diabetes (CFRD) [18], CF liver disease (CFLD) [19], lung disease [20, 21] and the colonization by $P$. aeruginosa [22]. However, environmental factors, such as the quality of health care, compliance to therapy [23], lifestyle, and socio-economic status [24] play a pivotal role in the outcome of CF.

The strong heterogeneity of CF impacts on the genetic counseling and on the reproductive planning of families that have CF affected children. In the present study, we evaluated a series of pairs of siblings with CF monitored since diagnosis to study the degree of clinical heterogeneity of the CF phenotype, assessing and correlating clinical aspects and complications of the disease.

\section{Methods}

\section{Patients}

The study population consisted of patients followed since diagnosis at $12 \mathrm{CF}$ specialized care centers in Italy who met diagnostic criteria for CF [25] and had at least one sibling suffering from CF. According to the current Italian legislation, we obtained from all patients (or from their legal guardian) the informed consent to use anonymously clinical data for research purposes.

\section{Methods}

Sweat chloride levels were tested according to guidelines [26]. We screened for a panel of mutations and for the most common CFTR rearrangements [27]; thus, we carried out gene sequencing (detection rate 95\%) [28, 29] in patients in which one or both mutations resulted undetected after first level analysis [30]. We analyzed 7 intragenic CFTR short tandem repeats [31] to verify that both members of four sibling-pairs carrying only one known mutation had the same CFTR genotype. Molecular analysis revealed more than 50 different CFTR mutations in our patients and only for a half of them functional studies had defined the molecular effect and the class; furthermore, some of these latter mutations may combine more defects and can be attributed to more classes [2]. Thus, we did not perform correlations between the CFTR genotype and clinical parameters. However, Additional file 1: Table S1 provides the CFTR genotype of each patient included in the study.

Meconium ileus was defined using the criteria described [15]. The forced expiratory volume $\left(\mathrm{FEV}_{1}\right)$, expressed as the percentage of predicted value for age, according to standardized reference equations for spirometry [32] was recorded. To avoid age-related differences between siblings of each pair, we recorded as current $\mathrm{FEV}_{1}$ the last value of the younger sibling and that of the older sibling at the same age. In the case of patients who had died or had undergone lung transplantation we recorded the last $\mathrm{FEV}_{1}$ and the value of the living or non-transplanted member of the sibling-pair at the same age. Given the inter-individual variability of $\mathrm{FEV}_{1}$ and the evolution of lung damage with age [33] the patients were classified as severe or mild according with the criteria by Schluchter et al., that take into account both the $\mathrm{FEV}_{1}$ value and age $[34,35]$. The airway colonization by $P$. aeruginosa was identified by sputum or oropharyngeal swab culture. Chronic infection was defined according to the modified Leeds criteria [36].

Fecal pancreatic elastase was evaluated annually and at least 3 months before enrollment. Pancreatic sufficiency was defined on the basis of fecal pancreatic elastase-1 higher than $200 \mathrm{mcg} / \mathrm{g}$ measured in the absence of acute pancreatitis or gastrointestinal diseases. Pancreatitis was defined as acute or chronic according to the report from International study group of pediatric pancreatitis [37] excluding all known causes of pancreatitis. Liver disease was evaluated by means of clinical, biochemical or ultrasonography abnormalities recorded in two consecutive examinations within a 3-month period, in the absence of other causes of congenital or acquired chronic liver disease [38]. Patients were considered as affected by CFLD when they had liver cirrhosis, considered as the extreme phenotype to define liver disease in our study, with imaging techniques showing nodular hepatic parenchyma and signs of portal hypertension [17]. A glucose tolerance test was performed annually in all patients with $\mathrm{CF}$ and the diagnosis of CFRD was made according to the standard American Diabetes Association criteria [39]. Finally, the history of nasal polyposis requiring surgery was evaluated.

\section{Statistics}

The concordance for disease (symptoms or complications) within sibling-pairs was calculated as the ratio between the number of pairs concordant for the symptom/ complication and the number of pairs in which at least one member had the symptom/complication [15].

\section{Results and discussion Study population}

We studied 208 patients with CF (median age: 30 years, range 12-61 years; 106 males); of these, 40 (19.2\%) were diagnosed by newborn screening (NBS) and 168 (80.8\%) by symptoms or by family history. All the 208 patients were over 12 years of age and $172 / 208$ patients $(82.7 \%)$ were over 18 years. The study included 95 pairs of siblings (22 pairs of females, 27 pairs of males and 46 pairs of one female and one male) and 6 sets of 3 siblings (2 including two males and one female, 2 including two females and one male and 2 including three females). 
In $80 / 101$ pairs $(79.2 \%)$ all the siblings were above 18 years of age.

\section{Pancreatic status}

As shown in Table 1, in our pairs of siblings we found a concordance for PI of $95.1 \%$ (i.e., only in three sibling-pairs the pancreatic status resulted discordant) confirming the known correlation between the pancreatic status and the CFTR genotype. However, pairs of siblings with the same CFTR mutations may have PS or $\mathrm{PI}$, and it is known that mutations like the R334W, the R347P, the 2789 + 5G > A [40], or the D1152H [41] may be associated with PS or PI. This means that the high degree of concordance for the pancreatic status found in siblings depends on the "whole" CFTR genotype (that is quite completely shared by siblings) including either mutations in the coding regions and variants in non-coding regions like the promoter or the intronic regions $[7,8]$ that together define the levels of residual activity of the CFTR protein at pancreatic level and thus may modulate the pancreatic status of each patient.

Table 1 compares the clinical characteristics and the complications in sib-pairs with different pancreatic status. In sib-pairs with PI, MI, severe lung disease, CFLD and CFRD occurred more frequently (even if the small number of cases preclude a statistical comparison) according to the current literature [42, 43].

Table 1 Concordance within sib-pairs for PI and correlation between the pancreatic status and meconium ileus (MI), severity of lung disease, CF liver disease (CFLD), CF related diabetes (CFRD) and recurrent panreatitis (RP) in 101 pairs of siblings with CF. N: absence of the symptom/complication

\begin{tabular}{lllll}
\hline Concordance within sib-pairs for PI (\%)95.1 & & & \\
\hline & & PI/PI & PI/PS & PS/PS \\
\hline Number of sib-pairs & & 58 & 3 & 40 \\
Meconium ileus: & MI/MI & 4 & 0 & 0 \\
& MI/N & 5 & 0 & 2 \\
& N/N & 49 & 3 & 38 \\
Lung disease: & Severe/severe & 6 & 0 & 0 \\
& Severe/mild & 15 & 1 & 5 \\
& Mild/mild & 37 & 2 & 35 \\
CF liver disease: & CFLD/CFLD & 3 & 2 & 0 \\
& CFLD/N & 11 & 0 & 2 \\
& N/N & 44 & 1 & 38 \\
CF related diabetes: & CFRD/CFRD & 5 & 0 & 1 \\
& CFRD/N & 11 & 3 & 2 \\
& N/N & 42 & 0 & 37 \\
Pancreatitis: & RP/RP & 1 & 0 & 1 \\
& RP/N & 1 & 0 & 6 \\
& N/N & 56 & 3 & 33 \\
\hline
\end{tabular}

Recurrent pancreatitis was significantly more frequent in sib-pairs with PS in agreement with the concept that recurrent pancreatitis in patients with $\mathrm{CF}$ is due to ductal plugging that typically occurs in patients with PS $[43,44]$. On the other hand, modifier genes other than CFTR may enhance the risk to develop recurrent/chronic pancreatitis $[45,46]$ explaining some cases of patients with PI that developed recurrent pancreatitis (Additional file 1: Table S1).

Interestingly, among the patients with PS we found MI in 2 cases, severe lung disease in 6 and complications such CFLD in 5 or CFRD in 7 cases (Additional file 1: Table S1). We are confident that our patients with PS would not develop PI later either because most patients with PS have at least one mild mutation and because their age is higher than that of patients with PI (mean 34.6 years, median 33 years for patients with PS versus a mean age of 28.0 years and a median of 25 years of patients with PI). Thus, a severe clinical phenotype may occur in a percentage of patients with PS. Considering that most patients with CF and PS are nowadays diagnosed by NBS, the presence of these complicated cases suggests that patients with PS would be monitored with the same care of patients with PI.

\section{Meconium ileus and DIOS}

We found a $36.4 \%$ of concordance for MI in sib-pairs, i.e., 4 pairs were concordant for $\mathrm{MI}$ and 7 pairs were discordant suggesting that in addition to the CFTR genotype other non-genetic and genetic factors contribute to the development of MI. Among the genetic ones, in CFTR-deficient mice, that is an excellent model for human MI, three potential modifier loci for MI were found on chromosomes 1, 9 and 10, respectively [47]. Subsequent studies in humans identified at least 2 modifier loci for MI [15] and thus, the SLC4A4 gene was candidate as modifier genes for MI in patients with CF [48]. Furthermore, a role of $\mathrm{KCNN} 4$ as a modifier gene of $\mathrm{MI}$ was suggested [16, 17].

We found five patients with CF that had DIOS; such complication was revealed in both the members of two sib-pairs and in a member of a further pair (Additional file 1: Table S1). Interestingly, none of the five patients experienced MI, reinforcing the view that DIOS, once considered the adult equivalent of MI, has an independent etiology [15].

\section{Lung disease}

We found 34/208 patients (16.4\%) with severe lung disease. The concordance for severe lung disease was $22.2 \%$, i.e., in 21 pairs the lung status was discordant (i.e., severe versus mild) between siblings (Fig. 1) while in 6 pairs both the siblings had a severe lung disease suggesting that environmental factors and genes inherited 


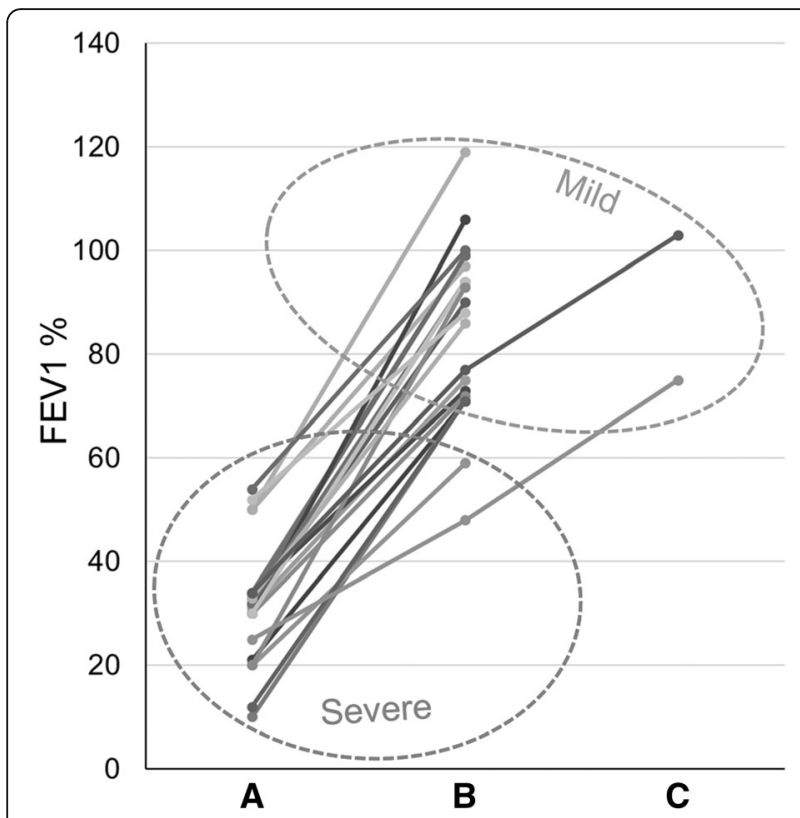

Fig. 1 FEV $1 \%$ of predicted for age in 21 pairs of siblings with cystic fibrosis discordant for the severity of lung disease. The classification as mild or severe was performed according to the criteria by Schluchter et al. [30] that take into account both the $\mathrm{FEV}_{1}$ value and age

independently by CFTR contribute to the pathogenesis of severe lung disease. This agree with the results of Vanscoy et al. on 231 pairs of siblings [49], and of Collaco et al. [21], that concluded that genetic and environmental factors contribute equally to lung function in patients with CF. Finally, an excellent study on 6365 patients with CF revealed five loci that modulate the severity of lung disease in patients with CF [20]. The severe lung disease correlated with PI (e.g., all the 6 pairs of siblings with severe lung disease had PI, see Additional file 1: Table S1) and with $P$. aeruginosa colonization (see below).

It is interesting to observe the longitudinal data of 25 patients from our study for which the values of $\mathrm{FEV}_{1}$ at the age of 12 years and at the age of 25 years or later were available (Fig. 2). Even if the number of cases is small, the classification of severe $(n=12)$ or mild $(n=13)$ lung disease performed at 12 years invariably coincides with that obtained in the adulthood in the same patient, suggesting that the $\mathrm{FEV}_{1} \%$ in young patients with $\mathrm{CF}$ is predictive of the lung function in the adult age.

On the other hand, it is known that structural lung damage is an early event in patients with CF [50]. This was revealed by high-resolution chest tomography [51] and by the presence of severe pulmonary inflammation and structural lung disease in still asymptomatic patients diagnosed by NBS [52].

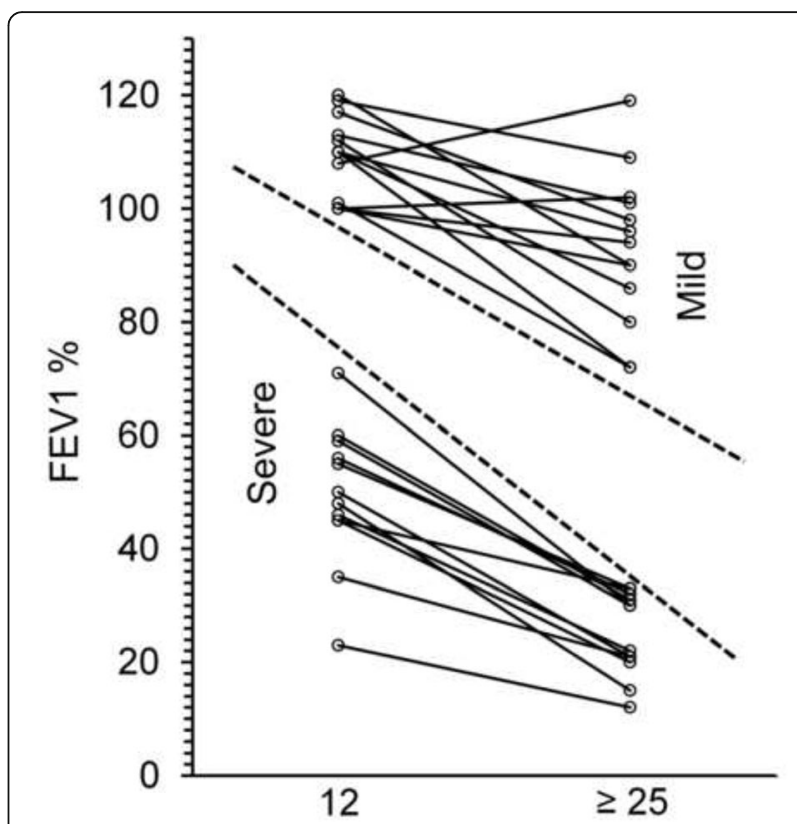

Fig. $2 \mathrm{FEV}_{1} \%$ of predicted for age in 25 patients with cystic fibrosis. For each patient we report the value measured at the age of 12 years and the current value at the age of 25 years or later. The classification of mild (13 cases) or severe (12 cases) was performed according to criteria by Schluchter et al. [30] that take into account both the FEV 1 value and age

\section{Colonization by Pseudomonas aeruginosa}

We found colonization by $P$. aeruginosa in 92/208 (44.2\%) patients with CF. Among our 101 pairs of siblings, we found colonization by $P$. aeruginosa in all the members of 34 sibling-pairs, among which the three siblings of two triplets and only one member of 20 sibling-pairs (and in two of three members of a triplet), with a high concordance for colonization (i.e., 61.8\%). This result agrees with previous studies on 50 [52] and 11 [19] pairs of siblings. Interestingly, among our siblings discordant for colonization, in $11 / 21$ cases both the siblings lived in the same house, and the sibling colonized by $P$. aeruginosa was colonized since at least 3 years. These data indicate a limited role of the environment in the colonization and confirms a contribution of CFTR genotype and genes inherited independently by CFTR that may predispose to colonization by $P$. aeruginos $a$, as reviewed by Cutting [3]. Nevertheless, we cannot rule out an early intervention (e.g. antibiotics) to prevent nosocomial infection in non-colonized siblings.

In patients with colonization there is a significantly higher occurrence of severe lung disease (data not shown). However, colonization is likely a consequence of the severe pulmonary damage more than a causal contribution. Indeed, the mean age of colonization in our patients was 18.5 years (median 22.6), while the occurrence of the structural lung damage is an early 
event in patients with CF (as discussed in the previous paragraph).

\section{CF liver disease}

We found CFLD in 24/208 (11.5\%) patients with CF. It is difficult to compare this figure with previous data because different parameters may be used to define CFLD (i.e., altered aminotransferase levels, focal biliary cirrhosis, US alterations, portal hypertension). As described in materials and methods, we used very stringent parameters to define CFLD and our results agree with the evidence that about $10 \%$ of patients with CF develop a severe liver damage and about 5\% require liver transplantation. Our data confirm that CFLD is an early event since it was diagnosed at a mean age of 14.7 years (median 15 years old, range 7-27 years) in agreement with the view that CFLD peaks in adolescence [42].

CFLD was found in both the members of 5 siblingpairs and in one member of 13 sibling-pairs (among which two triplets) and in two members of a further triplet. No previous data are available on the comparison of CFLD liver disease in siblings and in twins with CF, but the concordance for CFLD of $27.8 \%$ obtained in our sibling-pairs indicate a scarce contribution of genes in the pathogenesis of CFLD reinforcing the role of environmental, mostly still unknown, risk factors [38]. In fact, the largest two-stage control study (about 2000 patients with $\mathrm{CF}$ ) on modifier genes of CFLD revealed mutations in the SERPIN1 gene encoding for alpha-1-antitrypsin only in about $2 \%$ of patients with CFLD [19]. In agreement, among the 15 sibling-pairs discordant for CFLD, only in 2 cases the sibling suffering from CFLD had levels of serum alpha-1-antitrypsin under the lower reference limit, compatible with the deficiency of the protein, while the siblings free from CFLD had normal levels of the protein.

\section{Cystic fibrosis related diabetes (CFRD)}

We found CFRD in all the members of 6/101 siblingpairs (among which one triplet) and in one member of 16/101 sibling-pairs. The concordance for CFRD was $27.3 \%$ and this figure compares with that of $18.0 \%$ reported in a population of 588 sibling-pairs [53]. These data, added to the concordance for CFRD of $73.0 \%$ obtained in 68 pairs of monozygotic twins with CF [53] that share $100 \%$ of DNA, support the view that genetic modifiers play a marginal role in the development of diabetes in patients with CF. This is also confirmed by the observation that the occurrence of CFRD is not an early complication in patients with CF [39]. In fact, the diagnosis of CFRD in our patients was performed at the mean age of 32.2 years and in more than a half of patients $>30$ years. Furthermore, we excluded also the gender as a risk factor for CFRD: we found such complication in 13/106 males and in 15/102 females ( $p$ not significant). Most studies on larger populations reported the female gender as a risk factor for CFRD [42], but a more recent study on 588 sibling-pairs did not find a statistically significant role of gender as risk factor for CFRD [53].

As shown in Table 1, PI was significantly more frequent in sib-pairs with CFRD, confirming PI as a risk factor for CFRD since it causes a progressive pancreatic fibrosis that gradually damages the insulae [54]. However, observing that $7 / 28$ patients with CFRD had PS (Additional file 1: Table S1), we suggest that also CF patients with PS must be included in the annual screening for CFRD based on the glucose tolerance test [42].

In addition, CFLD contributes to the risk for CFRD [55] since we found a higher occurrence of CFLD among sib-pairs with CFRD than in those free from this complication. Finally, our data are in agreement with the view that severe lung disease is a risk factor for CFRD in turn $[56,57]$. In fact, in 19 sib-pairs in which one or both patients had CFRD, in 12 cases one or both the siblings had a severe lung disease, a condition observed only in $15 / 79$ pairs in which both the siblings were free from CFRD. This correlation is more evident in 16 siblingpairs discordant for CFRD, in which the sibling with CFRD, at the same age, had the worst $\mathrm{FEV}_{1} \%(p=0.004$, Wilcoxon signed rank test) in 14/16 cases (Fig. 3).

\section{Nasal polyposis}

We found nasal polyposis requiring surgery in both the siblings of 13 pairs and only in one sibling from 12 sibling-pairs (concordance for disease: 52.0\%). There are no previous data on sibling pairs to which compare our results. The poor correlation of nasal polyposis to other clinical manifestations such as the pancreatic status and the severity of lung disease (data not shown) imply that modifier genes play a role in determining nasal polyposis. In fact, a recent study firstly described the potential role of interferon-related developmental regulator 1 (a known modifier gene for CF pulmonary disease severity) as a modifier gene of nasal polyposis in patients with CF [58].

\section{Conclusions}

Our study confirms the clinical heterogeneity of CF also in a percentage of pairs of siblings with CF. Physicians involved in genetic counseling must be aware of a so wide and mostly unpredictable variability. Stochastic, environmental and genetic factors also independent by CFTR contribute to such variability, even if with a different weight on each variable (i.e., nasal polyposis and $P$. aeruginosa colonization may be more influenced by genetic factors while CFRD and CFLD or the severe lung disease may be influenced either by genetic and by 


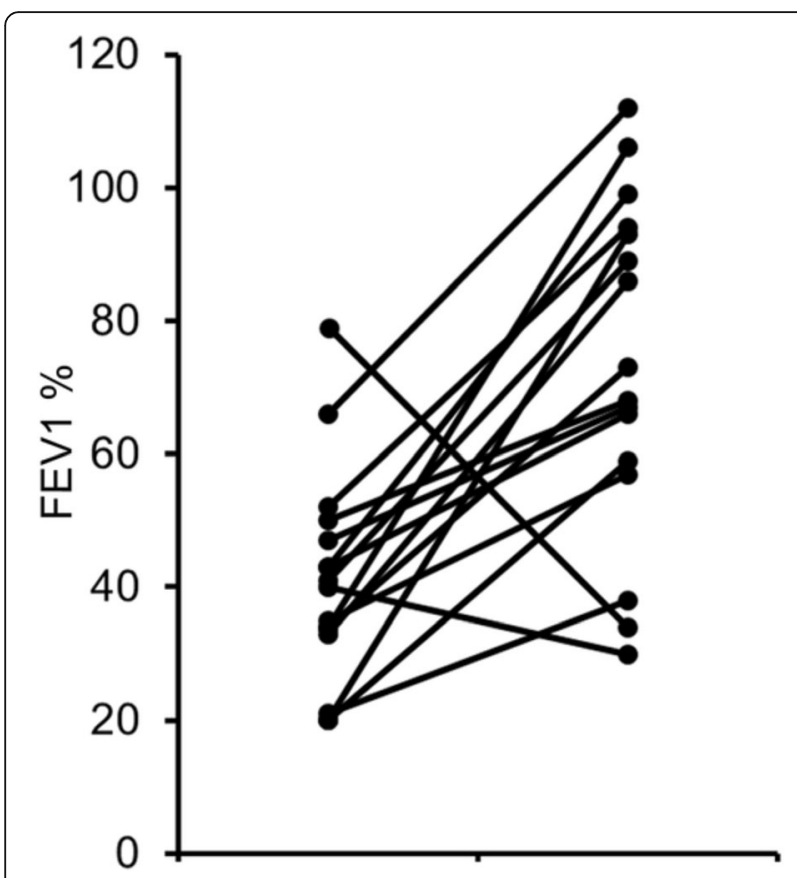

Fig. 3 Current $\mathrm{FEV}_{1} \%$ of predicted for age in 15 pairs of siblings discordant for cystic fibrosis related diabetes (CFRD). a sibling with CFRD; $\mathbf{b}$ sibling free from CFRD. We reported as current FEV the last value of the younger sibling and that of the older sibling at the same age

environmental factors). However other variables like medical care (that significantly improved in the last years), strongly influenced the clinical expression of each patient of our cohort that includes CF patients in the wide range between 12 to 61 years. Some working hypotheses emerged from our study: i) the classification of the lung damage as severe or mild based on the $\mathrm{FEV}_{1} \%$ assessed at the age of 12 years coincides with that obtained in the adulthood; ii) CFRD is influenced by the severity of liver disease; iii) a severe course of the disease (including the occurrence of complications) may occur in a percentage of patients with CF and PS suggesting that also such cases, usually revealed by NBS and once classified as mild CF, should be monitored as the patients with PI.

\section{Additional file}

Additional file 1: Table S1. Clinical and genetic data of the 208 patients with CF included in the study. (XLSX $44 \mathrm{~kb}$ )

\section{Abbreviations}

CF: Cystic fibrosis; CFLD: CF liver disease.; CFRD: CF-related diabetes; CFTR: Cystic fibrosis transmembrane conductance regulator; MI: Meconium ileus; PI: Pancreatic insufficiency; PS: Pancreatic sufficiency; SCL: Sweat chloride levels

\section{Acknowledgements}

We acknowledge the Società Italiana per lo studio della Fibrosi Cistica (SIFC) that stimulated this multicentric study, and the Ministero della Salute (Rome, Italy) L.548/93 for the regional research funding quote of years 2007-15. We thank Jean Ann Gilder (Scientific Communication srl., Naples, Italy) for editing the text.

\section{Funding}

This research did not receive any specific grant from funding agencies in the public, commercial or not-for-profit sectors.

\section{Availability of data and materials}

All data are available.

\section{Authors' contributions}

V.T. and G.C conceived and designed the study, analyzed and interpreted the data and wrote the manuscript; M.L. and D.S. contributed to data interpretation and manuscript preparation, collected the data and revised the manuscript; RB analyzed statistically data; C.C., AM. DL.,V.L, V.C., C.B., N.C., R.P., R.C., L.T., E.M., M.C., S.Q., M.S., A.B., A.E., A.M.D.L., F.Z., A.A., V.R. collected and analyzed the data and revised the manuscript. All authors read and approved the final manuscript.

\section{Ethics approval and consent to participate}

We obtained from all patients (or from their legal guardian) the written consent to participate. In according to National Guidelines, observational studies do not require the formal approval by the Ethics Committee. In any case, we asked to the local ethics committee (University of Naples Federico II) that replied confirming what above and sent us the reference of the guidelines: Ministry of Health, Italian Medicines Agency, Guidelines for the Classification and Conduct of Observational Drugs Studies (2008).

\section{Consent for publication}

Not applicable.

\section{Competing interests}

The authors declare that they have no competing interests.

\section{Publisher's Note}

Springer Nature remains neutral with regard to jurisdictional claims in published maps and institutional affiliations.

\section{Author details}

'Dipartimento di Pediatria, Centro Regionale Toscano per la Fibrosi Cistica, Azienda Ospedaliero-Universitaria Meyer, Viale Gaetano Pieraccini 24, 50139 Florence, Italy. ${ }^{2}$ Dipartimento di Biotecnologie Cellulari ed Ematologia, Istituto Pasteur Fondazione Cenci Bolognetti, Sapienza Università e Policlinico Umberto I, Rome, Italy. ${ }^{3}$ Centro Regionale Fibrosi Cistica, Centro Pediatrico Bambino Gesù Basilicata, AOR San Carlo, Potenza, Italy. ${ }^{4}$ Laboratorio di Genetica Medica, Ospedale Pediatrico Bambino Gesù, Rome, Italy. ${ }^{5}$ Centro Regionale Fibrosi Cistica, Fondazione IRCCS Ca' Granda, Ospedale Maggiore Policlinico, Università degli Studi di Milano, Milan, Italy. ${ }^{6}$ Freelance

Epidemiologist, Bergamo, Italy. ${ }^{7}$ Centro Regionale Fibrosi Cistica Adulti, Dipartimento di Scienze Mediche Traslazionali, Università di Napoli Federico II, Naples, Italy. ${ }^{8}$ Centro Regionale Fibrosi Cistica, U.O.C. Pneumologia, IRCCS G. Gaslini, Genua, Italy. ${ }^{9}$ Dipartimento di Medicina Molecolare e Biotecnologie Mediche, Università di Napoli Federico II, Naples, Italy.

${ }^{10} \mathrm{CEINGE-Biotecnologie} \mathrm{avanzate,} \mathrm{Naples,} \mathrm{Italy.}{ }^{11}$ Centro Regionale Fibrosi Cistica, Dipartimento Materno-Infantile, Ospedali Riuniti Ancona, Ancona, Italy. ${ }^{12}$ CRR Fibrosi Cistica, Ospedale dei Bambini, ARNAS Civico, Palermo, Italy. ${ }^{13}$ Dipartimento di Neuroscienze, Scienze Riproduttive ed

Odontostomatologica, Università di Napoli Federico II, Naples, Italy.

${ }^{14}$ Università Telematica Pegaso, Naples, Italy. ${ }^{15}$ Unità Regionale di Fibrosi Cistica, IRCCS Ospedale Pediatrico Bambino Gesù, Rome, Italy. ${ }^{16}$ Centro Regionale Fibrosi Cistica, Ospedale Giovanni Paolo II, Lamezia, Italy. ${ }^{17}$ Centro Regionale di supporto Fibrosi Cistica, Dipartimento di Pediatria, Università di Brescia, AO Spedali Civili, Brescia, Italy. ${ }^{18}$ Centro Fibrosi Cistica Regione Lazio, Dipartimento di Pediatria e Neuropsichiatria Infantile, Sapienza Università-Policlinico Umberto I, Rome, Italy. ${ }^{19}$ Centro Regionale Fibrosi Cistica, Sezione Pediatrica, Dipartimento di Scienze Mediche Traslazionali, Università di Napoli Federico II, Naples, Italy. ${ }^{20}$ Laboratorio di Genetica 
Medica, Fondazione IRCCS Policlinico Ca' Granda Ospedale, Milan, Italy. ${ }^{21}$ Ospedale dei Bambini G. Di Cristina, Centro Regionale Fibrosi Cistica, Palermo, Italy. ${ }^{22}$ Dipartimento di Bioscienze e Territorio, Università del Molise, Isernia, Italy.

\section{Received: 21 November 2017 Accepted: 12 December 2018} Published online: 22 December 2018

\section{References}

1. Jackson AD, Goss CH. Epidemiology of CF: how registries can be used to advance our understanding of the CF population. J Cyst Fibros. 2017;17: 30970. https://doi.org/10.1016/j.jcf.2017.11.013.

2. Veit G, Avramescu RG, Chiang AN, Houck SA, Cai Z, Peters KW, et al. From CFTR biology toward combinatorial pharmacotherapy: expanded classification of cystic fibrosis mutations. Mol Biol Cell. 2016;27:424-33.

3. Cutting GR. Cystic fibrosis genetics: from molecular understanding to clinical application. Nat Rev Genet. 2015;16:45-56.

4. Koch C, Cuppens H, Rainisio M, Madessani U, Harms H, Hodson M, et al. Investigators of the ERCF: comparison of major disease manifestations between patients with different classes of mutations. Pediatr Pulmonol. 2001;31:1-12.

5. McKone EF, Goss CH, Aitken ML. CFTR genotype as a predictor of prognosis in cystic fibrosis. Chest. 2006;130:1441-7.

6. Mekus F, Ballmann M, Bronsveld I, Bijman J, Veeze H, Tümmler B. Categories of delta F508 homozygous cystic fibrosis twin and sibling pairs with distinct phenotypic characteristics. Twin Res. 2000;3:277-93.

7. Giordano S, Amato F, Elce A, Monti M, lannone C, Pucci P, et al. Molecular and functional analysis of the large $5^{\prime}$ promoter region of CFTR gene revealed pathogenic mutations in CF and CFTR-related disorders. J Mol Diagn. 2013;15:331-40.

8. Amato F, Seia M, Giordano S, Elce A, Zarrilli F, Castaldo G, et al. Gene mutation in MicroRNA target sites of CFTR gene: a novel pathogenetic mechanism in cystic fibrosis? PlosONE. 2013;8:e60448.

9. Lucarelli M, Porcaro L, Biffignandi A, Costantino L, Giannone V, Alberti L, et al. A new targeted CFTR mutation panel based on next generation sequencing technology. J Mol Diagn. 2017;19:788-800.

10. Rossi T, Grandoni F, Mazzilli F, Quattrucci S, Antonelli M, Strom R, et al. High frequency of $(\mathrm{TG})_{m} T_{n}$ variant tracts in the cystic fibrosis transmembrane conductance regulator gene in men with high semen viscosity. Fertil Steril. 2004;82:1316-22

11. Lucarelli M, Bruno SM, Pierandrei S, Ferraguti G, Stamato A, Narzi F, et al. A genotypic-oriented view of CFTR genetics highlights specific mutational patterns underlying clinical macro-categories of cystic fibrosis. Mol Med. 2015;21:257-75

12. Lucarelli M, Narzi L, Pierandrei S, Bruno SM, Stamato A, d'Avanzo M, et al. A new complex allele of the CFTR gene partially explains the variable phenotype of the L997F mutation. Genet Med. 2010;12:548-55.

13. Terlizzi V, Castaldo G, Salvatore D, Lucarelli M, Raia V, Angioni A, et al. Genotype-phenotype correlation and functional studies in patients with cystic fibrosis bearing CFTR complex alleles. J Med Genet. 2017;54:224-35.

14. Salvatore F, Scudiero O, Castaldo G. Genotype-phenotype correlation in cystic fibrosis: the role of modifier genes. Am J Med Genet. 2002;111:88-95.

15. Blackman SM, Deering-Brose R, McWilliams R, Naughton $K$, Coleman B, Lai T, et al. Relative contribution of genetic and non-genetic modifiers to intestinal obstruction in cystic fibrosis. Gastroenterology. 2006;131:1030-9.

16. Zielenski J, Markiewicz D, Yuan X, Patel M, Sun L, Aznarez I, et al. Meconium ileus in cystic fibrosis neonates is associated with polymorphic markers in the calcium-activated potassium channel (KCNN4) gene. JPGN. 2004; 39:S405-6.

17. Philp AR, Riquelme T, Millar-Büchner P, González R, Sepúlveda FV, Pablo Cid $L$, et al. Kcnn4 is a modifier gene of intestinal cystic fibrosis preventing lethality in the Cftr-F508del mouse. Sci Rep. 2018;8:9320.

18. Blackman SM, Hsu S, Vanscoy LL, Collaco JM, Ritter SE, Naughton K, et al. Genetic modifiers play a substantial role in diabetes complicating cystic fibrosis. J Clin Endocrinol Metab. 2009;94:1302-9.

19. Bartlett JR, Friedman KJ, Ling SC, Pace RG, Bell SC, Bourke B, et al. Genetic modifiers of liver disease in cystic fibrosis. JAMA. 2009;302:1076-83.

20. Corvol H, Blackman SM, Boëlle PY, Gallins PJ, Pace RG, Stonebraker JR, et al. Genome-wide association meta-analysis identifies five modifier loci of lung disease severity in cystic fibrosis. Nat Commun. 2015;6:8382.
21. Collaco JM, Blackman SM, McGready J, Naughton KM, Cutting GR. Quantification of the relative contribution of environmental and genetic factors to variation in cystic fibrosis lung function. J Pediatr. 2010;157:802-7.

22. Green DM, Collaco JM, KE MD, Naughton KM, Blackman SM, Cutting GR. Heritability of respiratory infection with Pseudomonas aeruginosa in cystic fibrosis. J Pediatr. 2012;161:290-5.

23. Eakin MN, Riekert KA. The impact of medication adherence on lung health outcomes in cystic fibrosis. Curr Opin Pulm Med. 2013;19:687-91.

24. Schechter MS. Nongenetic influences on cystic fibrosis outcomes. Curr Opin Pulm Med. 2011;17:448-54.

25. Farrell PM, White TB, Ren CL, Hempstead SE, Accurso F, Derichs N, et al. Diagnosis of cystic fibrosis: consensus guidelines from the Cystic Fibrosis Foundation. J Pediatr. 2017;181S:S4-S15.e1.

26. LeGrys VA, Yankaskas JR, Quittell LM, Marshall BC, Mogayzel PJ Jr. Cystic Fibrosis Foundation. Diagnostic sweat testing: the Cystic Fibrosis Foundation guidelines. J Pediatr. 2007;151:85-9.

27. Tomaiuolo R, Sangiuolo F, Bombieri C, Bonizzato A, Cardillo G, Raia V, et al. Epidemiology and a novel procedure for large scale analysis of CFTR rearrangements in classic and atypical CF patients: a multicentric Italian study. J Cyst Fibros. 2008;7:347-51.

28. Lucarelli M, Narzi L, Piergentili R, Ferraguti G, Grandoni F, Quattrucci S, et al. A 96-well formatted method for exon and exon/intron boundary full sequencing of the CFTR gene. Anal Biochem. 2006;353:226-35.

29. Ferraguti G, Pierandrei S, Bruno SM, Ceci F, Strom R, Lucarelli M. A template for mutational data analysis of the CFTR gene. Clin Chem Lab Med. 2011;49:1447-51.

30. Dequeker E, Stuhrmann M, Morris MA, Casals T, Castellani C, Claustres M, et al. Best practice guidelines for molecular genetic diagnosis of cystic fibrosis and CFTR-related disorders: updated European recommendations. Eur J Hum Genet. 2009;17:51-65.

31. Elce A, Boccia A, Cardillo G, Giordano S, Tomaiuolo R, Paolella G, et al. Three novel CFTR polymorphic repeats improve segregation analysis for cystic fibrosis. Clin Chem. 2009:55:1372-9.

32. Quanjer PH, Stanojevic S, Cole TJ, Baur X, Hall GL, Culver BH, et al. ERS global lung function initiative. Multi-ethnic reference values for spirometry for the 3-95 year age range: the global lung function 2012 equations. Eur Respir J. 2012:40:1324-43.

33. Schluchter MD, Konstan MW, Drumm ML, Yankaskas JR, Knowles MR. Classifying severity of cystic fibrosis lung disease using longitudinal pulmonary function data. Am J Respir Crit Care Med. 2006;174:780-6.

34. Wang $X$, Dockery DW, WypiJ D, Fay ME, Ferris BG. Pulmonary function between 6 and 18 years of age. Pediatr Pulmunol. 1993;15:75-88.

35. Konstan MW, Wagener JS, Van Devanter DR. Characterizing aggressiveness and predicting future progression of CF lung disease. J Cyst Fibros. 2009; 8(Suppl 1):S15-9.

36. Lee TW, Brownlee KG, Conway SP, Denton M, Littlewood JM. Evaluation of a new definition for chronic Pseudomonas aeruginosa infection in cystic fibrosis patients. J Cyst Fibros. 2003;2:29-34

37. Morinville VD, Husain SZ, Bai H, Barth B, Alhosh R, Durie PR, et al. Definitions of pediatric pancreatitis and survey of present clinical practices. J Pediatr Gastroenterol Nutr. 2012;55:261-5.

38. Debray D, Kelly D, Houwen R, Strandvik B, Colombo C. Best practice guidance for the diagnosis and management of cystic fibrosis-associated liver disease. J Cyst Fibros. 2011:10:S29-36.

39. Kelly A, Moran A. Update on cystic fibrosis-related diabetes. J Cyst Fibros. 2013;12:318-31.

40. Castellani C, Cuppens H, Macek M, Cassiman JJ, Kerem E, Durie P, et al. Consensus on the use and interpretation of cystic fibrosis mutation analysis in clinical practice. J Cyst Fibros. 2008;7:179-96.

41. Terlizzi V, Carnovale V, Castaldo G, Castellani C, Cirilli N, Colombo C, et al. Clinical expression of patients with the D1152H CFTR mutation. J Cyst Fibrosis. 2015;14:447-52

42. Castellani C, Assael BM. Cystic fibrosis: a clinical view. Cell Mol Life Sci. 2017; 74:129-40.

43. Walkowiak J, Lisowska A, Blaszczynski M. The changing face of the exocrine pancreas in cystic fibrosis: pancreatic sufficiency, pancreatitis and genotype. Eur J Gastroenterol Hepatol. 2008;20:157-60.

44. Terlizzi V, Tosco A, Tomaiuolo R, Sepe A, Amato N, Casale A, et al. Prediction of acute pancreatitis risk based on PIP score in children with cystic fibrosis. J Cyst Fibros. 2014;13:579-84

45. Tomaiuolo AC, Sofia VM, Surace C, Majo F, Genovese S, Petrocchi S, et al. Relationship between CFTR and CTRC variants and the clinical phenotype in 
late-onset cystic fibrosis disease with chronic pancreatitis. J Mol Diagn. 2015; 17:171-8.

46. Sofia VM, Da Sacco L, Surace C, Tomaiuolo AC, Genovese S, Grotta S, et al. Extensive molecular analysis suggested the strong genetic heterogeneity of idiopathic chronic pancreatitis. Mol Med. 2016;26:22.

47. Norkina O, De Lisle RC. Potential genetic modifiers of the cystic fibrosis intestinal inflammatory phenotype on mouse chromosomes 1, 9, and 10. BMC Genet. 2005;6:29.

48. Dorfman R, Li W, Sun L, Wang Y, Sandford A, Paré PD, et al. Modifier gene study of meconium ileus in cystic fibrosis: statistical considerations and gene mapping results. Hum Genet. 2009;126:763-78.

49. Vanscoy LL, Balckman SM, Collaco JM, et al. Heriability of lung disease severity in cystic fibrosis. Am J Respir Crit Care Med. 2007;175:1036-43.

50. Kerem E, Viviani L, Zolin A, MacNeill S, Hatziagorou E, Ellemunter H, et al. Factors associated with FEV1 decline in cystic fibrosis: analysis of the ECFS patient registry. Eur Respir J. 2014;43:125-13.

51. Mott LS, Graniel KG, Park J, de Klerk NH, Sly PD, Murray CP, et al. Assessment of early bronchiectasis in young children with cystic fibrosis is dependent on lung volume. Chest. 2013;144:1193-8.

52. Sly PD, Brennan S, Gangell C, de Klerk N, Murray C, Mott L, et al. Lung disease at diagnosis in infants with cystic fibrosis detected by newborn screening. Am J Respir Crit Care Med. 2009;180:146-52.

53. Blackman SM, Commander CW, Watson C, et al. Genetic modifiers of cystic fibrosis-related diabetes. Diabetes. 2013;62:3627-35.

54. Picard E, Aviram M, Yahav Y, Rivlin J, Blau H, Bentur L, et al. Familial concordance of phenotype and microbial variation among siblings with CF. Ped Pulmunol. 2004;38:292-7.

55. Minicucci L, Lorini R, Giannattasio A, Colombo C, lapichino L, Reali MF, et al. Liver disease as risk factor for cystic fibrosis-related diabetes development. Acta Pediatr. 2007;96:736-9

56. Terliesner N, Vogel M, Steighardt A, Gausche R, Henn C, Hentschel J, et al. Cystic-fibrosis related-diabetes (CFRD) is preceded by and associated with growth failure and deteriorating lung function. J Pediatr Endocrinol Metab. 2017;30:815-21.

57. Hunt WR, Helfman BR, McCarty NA, Hansen JM. Advanced glycation end products are elevated in cystic fibrosis-related diabetes and correlate with worse lung function. J Cyst Fibros. 2016;15:681-8.

58. Baldan A, Lo Presti AR, Belpinati F, Castellani C, Bettin MD, Xumerle L, et al. IFRD1 gene polymorphisms are associated with nasal polyposis in cystic fibrosis patients. Rhinology. 2015;53:359-64.

Ready to submit your research? Choose BMC and benefit from:

- fast, convenient online submission

- thorough peer review by experienced researchers in your field

- rapid publication on acceptance

- support for research data, including large and complex data types

- gold Open Access which fosters wider collaboration and increased citations

- maximum visibility for your research: over $100 \mathrm{M}$ website views per year

At $\mathrm{BMC}$, research is always in progress.

Learn more biomedcentral.com/submissions 